Original title / titulo original: La ejecutoria del pleito contra don

Cristóbal Vaca de Castro: anatomía de un manuscrito "peruano»

del Archivo del Sacromonte

Author(s)/ autor(es):

Hélène Roy

Published originally as/ Publicado originalmente en: Estudios

Latinoamericanos, 36/37 (2016/2017), pp. 157-175

DOI: https://doi.org/10.36447/Estudios2017.v36-37.art7

Estudios Latinoamericanos is a journal published by Polish Society for Latin American Studies (Polskie Towarzystwo Studiów Latynoamerykanistycznych).

Polish Society for Latin American Studies is scholarly organization established to facilitate research on Latin America and to encourage and promote scientific and cultural cooperation between Poland and Latin America.

Estudios Latinoamericanos, revista publicada por la Sociedad Polaca de Estudios Latinoamericanos (Polskie Towarzystwo Studiów Latynoamerykanistycznych).

Sociedad Polaca de Estudios Latinoamericanos es una asociación científica fundada con el fin de desarrollar investigaciones científicas sobre América Latina y participar en la cooperación científica y cultural entre las sociedades de Polonia y América Latina. 


\title{
La ejecutoria del pleito contra don Cristóbal Vaca de Castro: anatomía de un manuscrito "peruano» del Archivo del Sacromonte
}

\author{
Hélène Roy
}

\section{Resumen}

Es conocida la figura de Cristóbal Vaca de Castro como gobernador del Perú (1541-1544), sin embargo muy poco se sabe de sus litigios con el Consejo de Indias a su regreso a España. La documentación conservada en el Sacromonte permite sondear los entresijos del poder metropolitano español del siglo XVI $y$ desvelar esta parcela poco explorada de la historia. Nos enfocaremos en la ejecutoria del pleito contra Vaca de Castro, siendo el documento más denso del fondo. Su análisis y la contextualización de las informaciones que contiene nos llevarán a describir todas las etapas y las implicaciones de un proceso que duró no menos de 11 años, con el fin de afinar nuestro conocimiento del perfil del principal inculpado y sus relaciones con su administración.

Palabras clave: Cristóbal Vaca de Castro, archivo del Sacromonte, justicia.

\section{Abstract}

THE WRIT OF EXECUTION AGAINST CRISTÓBAL VACA DE CASTRO: ANATOMY OF A 'PERUVIAN' MANUSCRIPT IN THE SACROMONTE ARCHIVES

Cristóbal Vaca de Castro is famously known as the governor of Peru (1541-1544), however, little is known of his conflicts with the law with the Council of the Indies on his return to Spain. Documentation kept in the archives of the Sacromonte makes it possible to investigate behind the scenes of the Spanish metropolitan power in the 16th century and to reveal this unexplored part of history. We will focus on the writ of execution against Vaca de Castro, as it is the richest document of the collection. Its analysis and the contextualization of its contents will lead us to the description of all the stages, the ins and outs of this trial that lasted no less than 11 years, in order to refine our knowledge on the profile of the main accused and on his relationship with the administration.

Keywords: Cristóbal Vaca de Castro, archives of the Sacromonte, justice.

Hélène Roy • Université de Poitiers / CRLA-Archivos, Francia. Correo-e: helene.roy@univ-poitiers.fr 
Con esta contribución queremos valorar el documento conservado en el Archivo secreto de la abadía del Sacromonte (Granada) cuyo título dice: Ejecutoria original del pleito seguido por el licenciado don Cristóbal Vaca de Castro, sobre los 21 capítulos que le puso el fiscal Villalobos, sobre la versación que tubo en el gobierno del Perú. Año 1545 (a partir de entonces «ejecutoria»). A pesar del vínculo notorio de este documento con la historia del Perú colonial temprano, los especialistas de esta área lo consultaron muy escasas veces. El peruanista Rubén Vargas Ugarte visitó el Sacromonte durante la década de 1950, sin embargo no fijó su atención en la ejecutoria sino en dos cartas inéditas que publicó entonces, una del obispo fray Vicente de Valverde y la otra de Francisco Pizarro (Vargas Ugarte 1959). Las primeras referencias al documento se deben al agustino Casiano García (1957); hubo que esperar más de treinta años para que se vuelva a señalar por Jesús Paniagua Pérez y María Isabel Viforcos Marinas, en su libro sobre el «gobernador y organizador» del Perú (1991). Finalmente, la ejecutoria fue mencionada e identificada entre los manuscritos «peruanos» del Archivo, en el catálogo realizado por María del Carmen Calero Palacios (1999). De modo que el documento permaneció dormido en la abadía y casi desconocido de los peruanistas. Gracias a la ayuda del padre Don Juan Sánchez Ocaña y de la Dra. María Luisa García Valverde, los investigadores tuvieron mayor acceso al fondo «Vaca de Castro» en los últimos tiempos, dando cabida a estudios importantes como los de Mariusz Ziółkowski y Álvaro Espinoza de la Borda (2010), Mariusz Ziółkowski y Ximena Fernández Fontenoy (2011) o de José Cárdenas Bun$\operatorname{sen}(2014)$.

La ejecutoria consta de 195 folios manuscritos que recopilan toda la defensa de Cristóbal Vaca de Castro en el pleito que le puso el fiscal del Consejo de Indias en 1545, el licenciado Juan de Villalobos. Esta documentación reunida por el abogado e hijo de Vaca de Castro constituye la pieza clave de su labor para disculpar a su padre durante los 11 años de pleito en los que permaneció encarcelado y sus bienes embargados. Primer arzobispo de Granada y fundador en 1610 de la abadía del Sacromonte, don Pedro de Castro y Quiñones emprendió una auténtica campaña de rehabilitación de su padre, entre cuyas modalidades cabe mencionar la biografía Elogio a Vaca de Castro encargada a Antonio de Herrera ${ }^{1}$, la serie de pinturas de autor anónimo en gloria del Gobernador del Perú ${ }^{2}$, así como una probable interferencia en el capítulo de Los Comentarios Reales dedicado al gobierno de Vaca de Castro en el Perú (Cárdenas Bunsen 2014). El empeño de don Pedro de Castro en esta empresa de rehabilitación no sólo deja vislumbrar su ambición - la fundación de la abadía responde al proyecto de constituir en torno a la imagen del padre difunto y su mausoleo (1614) el principio de un linaje ilustre que serviría sus propios intereses: el objetivo era construir una abadía monumental y atraer a la élite comercial peruana cediendo capellanías, sepulturas a distinguidos españoles enriquecidos en Perú y cargos de párroco a sus hijos o próximos - sino que atestigua la gravedad de los cargos que pesaron contra Vaca de Castro a su regreso de Perú. Sin embargo, 
los papeles del pleito nunca se han estudiado y, hasta la fecha, sólo se disponía de detalles diseminados en fuentes indirectas ${ }^{3}$.

La transcripción paleográfica de la ejecutoria ${ }^{4}$ permite colmar este vacío. Los documentos constitutivos del pleito, en los que aparecen los cargos, las peticiones de revisión, los interrogatorios, las condenas, etc., se yuxtaponen con distintas pruebas incorporadas tanto por la acusación como la defensa. Éstas constituyen sin duda las partes más interesantes de la ejecutoria ya que proporcionan nuevos elementos de contexto sobre el gobierno de Cristóbal Vaca de Castro en el Perú. Para facilitar su lectura, elaboramos una nomenclatura completa de la ejecutoria.

\begin{tabular}{|c|c|c|c|c|c|}
\hline $\mathrm{N}^{\circ}$. & Título / Tema & Autor(es) & Lugar & Fecha & Folio \\
\hline 1 & $\begin{array}{l}\text { Relación sobre el pleito que se } \\
\text { trató en el Consejo de Indias } \\
\text { entre el fiscal Villalobos y } \\
\text { Cristóbal Vaca de Castro [dos } \\
\text { acusaciones de } 21 \text { capítulos, la } \\
\text { una en } 29.06 .1545 \text {, la otra en } \\
20.07 .1545 \text { ] }\end{array}$ & El Rey & $s / 1$ & $s / f$ & $1 \mathrm{r}-4 \mathrm{r}$ \\
\hline 2 & $\begin{array}{l}\text { Testimonio [Cristóbal Vaca } \\
\text { de Castro se desembarcó el } \\
\text { 27.05.1545 en Lisboa sin licencia } \\
\text { del maestre] }\end{array}$ & \begin{tabular}{|l} 
Alonso Pérez \\
Granillo, \\
escribano de la \\
nao nombrada \\
Santiago \\
\end{tabular} & $s / 1$ & $s / f$ & $4 r-4 v$ \\
\hline 3 & $\begin{array}{l}\text { Carta al Rey [sobre los servicios } \\
\text { de Cristóbal Vaca de Castro] }\end{array}$ & $\begin{array}{l}\text { Cabildo de La } \\
\text { Plata }\end{array}$ & La Plata & 17.12 .1543 & $4 v-9 r$ \\
\hline 4 & \begin{tabular}{|l|} 
Carta al Rey [sobre los servicios \\
de Cristóbal Vaca de Castro]
\end{tabular} & \begin{tabular}{|l|} 
Cabildo de San \\
Juan de la Frontera \\
\end{tabular} & $\begin{array}{l}\text { San Juan de } \\
\text { la Frontera }\end{array}$ & 12.01 .1544 & $9 r-9 v$ \\
\hline 5 & \begin{tabular}{|l|} 
Carta al Rey [sobre los servicios \\
de Cristóbal Vaca de Castro]
\end{tabular} & \begin{tabular}{|l|} 
Cabildo de \\
Arequipa
\end{tabular} & Arequipa & 07.07 .1543 & $9 \mathrm{v}-11 \mathrm{r}$ \\
\hline 6 & $\begin{array}{l}\text { Comisión del Consejo de Indias } \\
\text { para que el lic. Salmerón tomase } \\
\text { confesión a Cristóbal Vaca de } \\
\text { Castro. Interrogatorio }\end{array}$ & \begin{tabular}{|l|} 
Martín de \\
Ramoyn, \\
escribano de su \\
Majestad e oficial \\
del secretario Juan \\
de Sámano \\
\end{tabular} & Valladolid & 04.07 .1545 & $11 \mathrm{r}-18 \mathrm{r}$ \\
\hline 7 & $\begin{array}{l}\text { Juramento y confesión de } \\
\text { Cristóbal Vaca de Castro }\end{array}$ & \begin{tabular}{|l|} 
Martín de \\
Ramoyn, \\
escribano de su \\
Majestad e oficial \\
del secretario Juan \\
de Sámano \\
\end{tabular} & Valladolid & 04.07 .1545 & $18 \mathrm{r}-46 \mathrm{v}$ \\
\hline 8 & $\begin{array}{l}\text { Petición de traslado de las } \\
\text { acusaciones a Cristóbal Vaca de } \\
\text { Castro }\end{array}$ & Consejo de Indias & $\mathrm{s} / \mathrm{l}$ & $\mathrm{s} / \mathrm{f}$ & $46 v$ \\
\hline 9 & $\begin{array}{l}\text { Petición de reconvención contra } \\
\text { el fiscal Villalobos }\end{array}$ & \begin{tabular}{|l|}
$\begin{array}{l}\text { Cristóbal Vaca de } \\
\text { Castro }\end{array}$ \\
\end{tabular} & $s / 1$ & $s / f$ & $46 v-47 r$ \\
\hline 10 & $\begin{array}{l}\text { Carta a Cristóbal Vaca de Castro } \\
\text { [consigue el derecho de hacer } \\
\text { justicia en Perú] }\end{array}$ & El Rey & $\begin{array}{c}\text { s/l } \\
{[\text { Monzón] }}\end{array}$ & 08.08 .1542 & $47 \mathrm{r}-47 \mathrm{v}$ \\
\hline
\end{tabular}




\begin{tabular}{|c|c|c|c|c|c|}
\hline 11 & $\begin{array}{l}\text { Carta a los oficiales de Perú } \\
\text { [para que den obediencia a } \\
\text { Cristóbal Vaca de Castro] }\end{array}$ & El Rey & Monzón & 08.08 .1542 & $47 v-48 v$ \\
\hline 12 & $\begin{array}{l}\text { Carta a Cristóbal Vaca de } \\
\text { Castro [para informarle de la } \\
\text { nominación de Blasco Núñez } \\
\text { Vela como Virrey de Perú] }\end{array}$ & El Príncipe & Valladolid & 13.09 .1543 & $48 v-50 r$ \\
\hline 13 & $\begin{array}{l}\text { Carta a Cristóbal Vaca de Castro } \\
\text { [sobre el bien que hizo en la } \\
\text { pacificación de los reinos de } \\
\text { Perú con la batalla de Chupas] }\end{array}$ & Cabildo del Cuzco & Cuzco & $\begin{array}{l}23.09 . \\
{[1542]}\end{array}$ & $50 \mathrm{r}-51 \mathrm{r}$ \\
\hline 14 & $\begin{array}{l}\text { Carta a Cristóbal Vaca de } \\
\text { Castro [designado librador de } \\
\text { esta república contra la tiranía } \\
\text { almagrista / sobre la destrucción } \\
\text { de los indios cargadores ] }\end{array}$ & Cabildo de Trujillo & Trujillo & 20.10 .1542 & $51 \mathrm{r}-51 \mathrm{v}$ \\
\hline 15 & $\begin{array}{l}\text { Carta a Cristóbal Vaca de Castro } \\
\text { [sobre la gran gratificación } \\
\text { que hizo a su Majestad con la } \\
\text { victoria de Chupas / sobre la } \\
\text { guerra entre Francia y España / } \\
\text { sobre los cambios de presidencia } \\
\text { en el Consejo de Indias] }\end{array}$ & $\begin{array}{l}\text { El Obispo de Los } \\
\text { Reyes [Jerónimo } \\
\text { de Loaysa] }\end{array}$ & San Miguel & $\begin{array}{c}27.03 . \\
{[1543]}\end{array}$ & $51 v-52 v$ \\
\hline 16 & $\begin{array}{l}\text { Carta a Cristóbal Vaca de Castro } \\
\text { [sobre el descubrimiento de } \\
\text { nuevas tierras / sobre el envío de } \\
\text { una joya] }\end{array}$ & Diego de Rojas & Tucumán & 04.08 .1543 & $52 \mathrm{v}-53 \mathrm{r}$ \\
\hline 17 & $\begin{array}{l}\text { Carta a Cristóbal Vaca de Castro } \\
\text { [sobre la mala intención que } \\
\text { tiene "aquella gente" (¿Gonzalo } \\
\text { Pizarro?) de ocupar los puertos } \\
\text { de Panamá y Nombre de Dios] }\end{array}$ & $\begin{array}{l}\text { ¿Cabildo de } \\
\text { Panamá? } \\
\text { (Fernando de } \\
\text { Carmona, Juan } \\
\text { de Zavala, Alonso } \\
\text { de Almaraz, Juan } \\
\text { Gómez de Anaya, } \\
\text { Andrés de Areila) }\end{array}$ & Panamá & 09.12 .1544 & $53 \mathrm{r}$ \\
\hline 18 & $\begin{array}{l}\text { Testimonio de los señores } \\
\text { alcaldes y regidores de Panamá } \\
\text { [el lic. Cristóbal Vaca de } \\
\text { Castro dijo que después de } \\
\text { preso el virrey Núñez Vela, } \\
\text { Gonzalo Pizarro compró un } \\
\text { navío para enviar gente de } \\
\text { guerra a la ciudad de Panamá } \\
\text { y echar al virrey en Nombre de } \\
\text { Dios / el lic. se alzó contra el } \\
\text { navío y rindió al maestre y los } \\
\text { marineros] }\end{array}$ & $\begin{array}{l}\text { Melchor de } \\
\text { Vitoria, escribano } \\
\text { del cabildo de } \\
\text { Panamá }\end{array}$ & Panamá & 03.12 .1544 & $53 \mathrm{r}-53 \mathrm{v}$ \\
\hline 19 & $\begin{array}{l}\text { Presentación de la petición de } \\
\text { Mauricio Zapata, en nombre de } \\
\text { Cristóbal Vaca de Castro, a los } \\
\text { alcaldes y regidores de Panamá } \\
\text { [que pongan guarda y recaudo } \\
\text { del navío] }\end{array}$ & $\begin{array}{l}\text { Francisco de } \\
\text { Santander, } \\
\text { escribano del } \\
\text { cabildo de Panamá } \\
\text { (por fe de Melchor } \\
\text { de Vitoria) } \\
\end{array}$ & Panamá & 12.12 .1544 & $53 \mathrm{v}-54 \mathrm{r}$ \\
\hline
\end{tabular}




\begin{tabular}{|c|c|c|c|c|c|}
\hline 20 & \begin{tabular}{|l|} 
Respuesta de los alcaldes y \\
regidores de Panamá a Cristóbal \\
Vaca de Castro [rechazo]. \\
Traslado al fiscal Villalobos \\
\end{tabular} & $\begin{array}{l}\text { Melchor de } \\
\text { Vitoria, escribano } \\
\text { del cabildo de } \\
\text { Panamá }\end{array}$ & Panamá & 12.12 .1544 & $54 \mathrm{r}$ \\
\hline 21 & $\begin{array}{l}\text { Oposición a la reconvención } \\
\text { que puso Cristóbal Vaca } \\
\text { de Castro contra el fiscal } \\
\text { Villalobos y petición para que } \\
\text { se proceda contra él. Sentencia } \\
\text { interlocutoria } \\
\end{array}$ & $\begin{array}{l}\text { El lic. Villalobos, } \\
\text { fiscal del Consejo } \\
\text { de Indias }\end{array}$ & $s / 1$ & $\mathrm{~s} / \mathrm{f}$ & $54 \mathrm{r}-54 \mathrm{v}$ \\
\hline 22 & \begin{tabular}{|l} 
Fragmentos de los \\
interrogatorios de Cristóbal \\
Vaca de Castro para probar lo \\
que sirvió en el Perú \\
\end{tabular} & ¿Escribano? & $s / 1$ & $\mathrm{~s} / \mathrm{f}$ & $54 \mathrm{v}-106 \mathrm{v}$ \\
\hline 23 & \begin{tabular}{|l|} 
Autos para que se publicasen las \\
probanzas de Cristóbal Vaca de \\
Castro y se viesen las probanzas \\
que presentase el fiscal \\
Villalobos hasta la sentencia \\
definitiva. \\
\end{tabular} & Consejo de Indias & $\mathrm{s} / \mathrm{l}$ & $\mathrm{s} / \mathrm{f}$ & $106 \mathrm{v}$ \\
\hline 24 & $\begin{array}{l}\text { Testimonio de la presentación } \\
\text { que hizo el lic. García León, } \\
\text { fiscal de justicia de su Majestad, } \\
\text { de ciertas escrituras }\end{array}$ & $\begin{array}{l}\text { ¿Francisco Paez, } \\
\text { escribano de su } \\
\text { Majestad? }\end{array}$ & $\begin{array}{l}\text { s/l [iSan } \\
\text { Juan de la } \\
\text { Frontera?] }\end{array}$ & $\begin{array}{c}\mathrm{s} / \mathrm{f}[\dot{i} 08.09 . \\
1542 ?]\end{array}$ & $107 \mathrm{r}$ \\
\hline 25 & $\begin{array}{l}\text { Denuncia y acusación contra } \\
\text { Diego de Almagro y sus } \\
\text { secuaces }\end{array}$ & $\begin{array}{l}\text { Lic. García de } \\
\text { León, fiscal de } \\
\text { la justicia de su } \\
\text { Majestad } \\
\end{array}$ & Jauja & 16.08 .1542 & $107 \mathrm{r}-119 \mathrm{v}$ \\
\hline 26 & $\begin{array}{l}\text { Testimonio de la acusación que } \\
\text { el lic. García de León presentó } \\
\text { ante Cristóbal Vaca de Castro }\end{array}$ & \begin{tabular}{|l|} 
Francisco Paez, \\
escribano de su \\
Majestad \\
\end{tabular} & $\begin{array}{l}\text { San Juan de } \\
\text { la Frontera }\end{array}$ & 08.09 .1542 & $119 \mathrm{v}-122 \mathrm{r}$ \\
\hline 27 & $\begin{array}{l}\text { Carta a Cristóbal Vaca de Castro } \\
\text { [sobre la gobernación de Nueva } \\
\text { Toledo / sobre las negociaciones } \\
\text { de paz con Manco Inca] }\end{array}$ & Diego de Almagro & Vilcas & 04.09 .1542 & $122 \mathrm{r}-124 \mathrm{v}$ \\
\hline 28 & $\begin{array}{l}\text { Carta a Cristóbal Vaca de Castro } \\
\text { [sobre la lealtad a Diego de } \\
\text { Almagro] }\end{array}$ & \begin{tabular}{|l} 
Capitanes \\
almagristas (Juan \\
Balsa, Diego de \\
Hozes, Diego \\
Méndez, Juan \\
Tello, Cárdenas, \\
Martín de Bilbao, \\
Pedro de Candia, \\
Martincote, \\
Juan Gutiérrez \\
Maraber, Juan de \\
Olea, Pedro de \\
Oñate, Juan Pérez)
\end{tabular} & Vilcas & 04.09 .1542 & $124 \mathrm{v}-126 \mathrm{r}$ \\
\hline
\end{tabular}




\begin{tabular}{|c|c|c|c|c|c|}
\hline 29 & $\begin{array}{l}\text { Relación de las decisiones de } \\
\text { Cristóbal Vaca de Castro[a } \\
\text { pesar de la petición del fiscal } \\
\text { García de León, decide mandar } \\
\text { palabras benévolas y persuasivas } \\
\text { a Diego de Almagro y sus } \\
\text { secuaces] }\end{array}$ & $\begin{array}{l}\text { Francisco Paez, } \\
\text { Pedro López, } \\
\text { escribanos de su } \\
\text { Majestad }\end{array}$ & $\begin{array}{l}\text { San Juan de } \\
\text { la Frontera }\end{array}$ & 09.09 .1542 & $126 r-127 r$ \\
\hline 30 & $\begin{array}{l}\text { Carta a Diego de Almagro [para } \\
\text { que se venga de paz] }\end{array}$ & \begin{tabular}{|l|} 
Cristóbal Vaca de \\
Castro
\end{tabular} & $\begin{array}{l}\text { San Juan de } \\
\text { la Frontera } \\
\end{array}$ & 08.09 .1542 & $127 \mathrm{r}-127 \mathrm{v}$ \\
\hline 31 & $\begin{array}{l}\text { Carta a los capitanes almagristas } \\
\text { [para que se vengan de paz] }\end{array}$ & $\begin{array}{l}\text { Cristóbal Vaca de } \\
\text { Castro }\end{array}$ & $\begin{array}{l}\text { San Juan de } \\
\text { la Frontera }\end{array}$ & 08.09 .1542 & $127 \mathrm{v}$ \\
\hline 32 & $\begin{array}{l}\text { Seguro para los que se vienen } \\
\text { de paz }\end{array}$ & \begin{tabular}{|l|} 
Cristóbal Vaca de \\
Castro
\end{tabular} & $\begin{array}{l}\text { San Juan de } \\
\text { la Frontera }\end{array}$ & 08.09 .1542 & $128 \mathrm{r}-128 \mathrm{v}$ \\
\hline 33 & $\begin{array}{l}\text { Provisión que nombra a } \\
\text { Cristóbal Vaca de Castro como } \\
\text { gobernador del Perú [trasladada } \\
\text { a los almagristas] }\end{array}$ & El Rey & Madrid & 09.09 .1540 & $128 \mathrm{v}-129 \mathrm{r}$ \\
\hline 34 & $\begin{array}{l}\text { Provisión a Diego de Almagro } \\
\text { y sus secuaces [plazo para que } \\
\text { vengan de paz] }\end{array}$ & $\begin{array}{l}\text { Cristóbal Vaca de } \\
\text { Castro }\end{array}$ & $\begin{array}{l}\text { San Juan de } \\
\text { la Frontera }\end{array}$ & 08.09 .1542 & $129 v-133 r$ \\
\hline 35 & $\begin{array}{l}\text { Testimonio de que las cartas y } \\
\text { provisiones de Cristóbal Vaca } \\
\text { de Castro se entregaron en } \\
\text { duplicado a los mensajeros de } \\
\text { Diego de Almagro }\end{array}$ & $\begin{array}{l}\text { Francisco Paez, } \\
\text { Pedro López, } \\
\text { escribanos de su } \\
\text { Majestad }\end{array}$ & $\begin{array}{l}\text { San Juan de } \\
\text { la Frontera }\end{array}$ & 08.09 .1542 & $133 r-133 v$ \\
\hline 36 & $\begin{array}{l}\text { Testimonio de la recepción } \\
\text { de cartas de respuesta a los } \\
\text { mensajes del } 08.09 .1542\end{array}$ & $\begin{array}{l}\text { Francisco Paez, } \\
\text { escribano de su } \\
\text { Majestad }\end{array}$ & $\begin{array}{l}\text { San Juan de } \\
\text { la Frontera }\end{array}$ & 12.09 .1542 & $133 \mathrm{v}$ \\
\hline 37 & Carta a Cristóbal Vaca de Castro & Diego de Almagro & Vilcas & 11.09 .1542 & $133 \mathrm{v}-134 \mathrm{r}$ \\
\hline 38 & Carta a Cristóbal Vaca de Castro & \begin{tabular}{|l} 
Capitanes \\
almagristas (Juan \\
Balsa, Diego de \\
Hozes, Diego \\
Méndez, Juan \\
Tello, Cárdenas, \\
Martín de Bilbao, \\
Pedro de Candia, \\
Martincote, \\
Juan Gutiérrez \\
Maraber, Juan de \\
Olea, Pedro de \\
Oñate, Juan Pérez) \\
\end{tabular} & Vilcas & 11.09 .1542 & $134 \mathrm{r}-134 \mathrm{v}$ \\
\hline 39 & $\begin{array}{l}\text { Testimonio de juramento de } \\
\text { los mensajeros de que han } \\
\text { entregado las cartas a Diego } \\
\text { de Almagro y sus aliados. } \\
\text { Testimonio de las respuestas } \\
\text { [parten del asiento de Vilcas } \\
\text { para desbaratar a Cristóbal } \\
\text { Vaca de Castro / ahorcaron al } \\
\text { mensajero Alonso García] }\end{array}$ & $\begin{array}{l}\text { Francisco Paez, } \\
\text { escribano de su } \\
\text { Majestad }\end{array}$ & $\begin{array}{l}\text { s/l [San } \\
\text { Juan de la } \\
\text { Frontera] }\end{array}$ & $\begin{array}{l}\mathrm{s} / \mathrm{f}[12.09 . \\
1542]\end{array}$ & $134 v-135 v$ \\
\hline
\end{tabular}




\begin{tabular}{|c|c|c|c|c|c|}
\hline 40 & $\begin{array}{l}\text { Testimonio de la acusación } \\
\text { que hizo el lic. García de León, } \\
\text { promotor fiscal de la justicia, } \\
\text { contra Diego de Almagro y sus } \\
\text { secuaces }\end{array}$ & $\begin{array}{l}\text { Francisco Paez, } \\
\text { escribano de su } \\
\text { Majestad }\end{array}$ & Chupas & $\begin{array}{l}10.09 .1542 \\
\text { [sic: debe } \\
\text { ser } 16.09]\end{array}$ & $135 \mathrm{v} .137 \mathrm{r}$ \\
\hline 41 & $\begin{array}{l}\text { Sentencia contra Diego de } \\
\text { Almagro y sus secuaces }\end{array}$ & $\begin{array}{l}\text { Cristóbal Vaca de } \\
\text { Castro }\end{array}$ & Chupas & 16.09 .1542 & $137 r-139 r$ \\
\hline 42 & $\begin{array}{l}\text { Testimonio de que la sentencia } \\
\text { se pregonó y de los sucesos de } \\
\text { la batalla }\end{array}$ & \begin{tabular}{|l|} 
Francisco Paez, \\
Pedro López, \\
escribanos de su \\
Majestad \\
\end{tabular} & $s / 1$ & $\mathrm{~s} / \mathrm{f}$ & $139 \mathrm{r}-142 \mathrm{v}$ \\
\hline 43 & $\begin{array}{l}\text { Pregón mandado por Diego de } \\
\text { Almagro a sus hombres }\end{array}$ & Diego de Almagro & $\mathrm{s} / 1$ [Cuzco] & $\begin{array}{c}\mathrm{s} / \mathrm{f}[30.04 . \\
1542]\end{array}$ & $142 \mathrm{v}-147 \mathrm{r}$ \\
\hline 44 & $\begin{array}{l}\text { Testimonio que se oyó pregonar } \\
\text { los capítulos precedentes }\end{array}$ & \begin{tabular}{|l} 
Diego de \\
Escalante, \\
escribano de \\
Cuzco \\
\end{tabular} & Cuzco & 30.04 .1542 & $147 \mathrm{r}$ \\
\hline 45 & $\begin{array}{l}\text { Sentencia definitiva del Consejo } \\
\text { de Indias sobre el pleito que } \\
\text { opone el fiscal Villalobos y } \\
\text { Cristóbal Vaca de Castro }\end{array}$ & $\begin{array}{l}\text { Lic. Gregorio } \\
\text { López, Lic. Tello } \\
\text { de Sandoval, } \\
\text { Dr. Ribadeneyra, } \\
\text { Lic. Bribiesca, del } \\
\text { Consejo de Indias } \\
\end{array}$ & Valladolid & 19.04 .1554 & $147 \mathrm{r}-153 \mathrm{v}$ \\
\hline 46 & $\begin{array}{l}\text { Notificación de la sentencia al } \\
\text { lic. Agreda, fiscal en el Consejo } \\
\text { de Indias, y a Juan de Oribe, } \\
\text { procurador de Cristóbal Vaca } \\
\text { de Castro }\end{array}$ & $\begin{array}{l}\text { Lic. Gregorio } \\
\text { López, Lic. Tello } \\
\text { de Sandoval, } \\
\text { Dr. Ribadeneyra, } \\
\text { Lic. Bribiesca, del } \\
\text { Consejo de Indias } \\
\end{array}$ & Valladolid & 21.04 .1554 & $153 \mathrm{v}$ \\
\hline 47 & $\begin{array}{l}\text { Peticiones en nombre de } \\
\text { Cristóbal Vaca de Castro en el } \\
\text { Consejo de Indias }\end{array}$ & $\begin{array}{l}\text { Juan de Oribe, } \\
\text { procurador de } \\
\text { Cristóbal Vaca de } \\
\text { Castro }\end{array}$ & Valladolid & 30.04 .1554 & $153 \mathrm{v}-177 \mathrm{r}$ \\
\hline 48 & $\begin{array}{l}\text { Petición del lic. Agreda en el } \\
\text { Consejo de Indias }\end{array}$ & Lic. Agreda, fiscal & Valladolid & 11.05 .1554 & $177 \mathrm{r}$ \\
\hline 49 & $\begin{array}{l}\text { Peticiones en nombre de } \\
\text { Cristóbal Vaca de Castro en el } \\
\text { Consejo de Indias }\end{array}$ & $\begin{array}{l}\text { Juan de Oribe, } \\
\text { procurador de } \\
\text { Cristóbal Vaca de } \\
\text { Castro } \\
\end{array}$ & Valladolid & $s / f$ & $177 \mathrm{r}-177 \mathrm{v}$ \\
\hline 50 & $\begin{array}{l}\text { Auto del Consejo de Indias } \\
\text { sobre el pleito que opone el } \\
\text { fiscal Agreda y Cristóbal Vaca } \\
\text { de Castro }\end{array}$ & Consejo de Indias & Valladolid & 14.08 .1554 & $177 \mathrm{v}-179 \mathrm{v}$ \\
\hline 51 & $\begin{array}{l}\text { Auto del Consejo de Indias } \\
\text { sobre el pleito que opone el } \\
\text { fiscal Agreda y Cristóbal Vaca } \\
\text { de Castro [confirma el auto } \\
\text { precedente] }\end{array}$ & Consejo de Indias & Valladolid & 18.09 .1554 & $\begin{array}{l}179 \mathrm{v}- \\
180 \mathrm{r}\end{array}$ \\
\hline 52 & $\begin{array}{l}\text { Auto del Consejo de Indias sobre } \\
\text { el pleito que opone el fiscal Agre- } \\
\text { da y Cristóbal Vaca de Castro } \\
\text { [confirma el auto precedente] }\end{array}$ & Consejo de Indias & Valladolid & 17.12 .1554 & $180 \mathrm{r}-180 \mathrm{v}$ \\
\hline
\end{tabular}




\begin{tabular}{|c|c|c|c|c|c|}
\hline 53 & $\begin{array}{l}\text { Auto del Consejo de Indias } \\
\text { sobre el pleito que opone el } \\
\text { fiscal Agreda y Cristóbal Vaca } \\
\text { de Castro [confirma el auto } \\
\text { precedente] }\end{array}$ & Consejo de Indias & Valladolid & 25.01 .1555 & $180 \mathrm{v}-181 \mathrm{r}$ \\
\hline 54 & $\begin{array}{l}\text { Testimonio presentado por } \\
\text { Cristóbal Vaca de Castro [sobre } \\
\text { su embarque para América] }\end{array}$ & $\begin{array}{l}\text { Pedro Fernández, } \\
\text { escribano de su } \\
\text { Majestad } \\
\end{array}$ & $\begin{array}{c}\text { San } \\
\text { Lúcar de } \\
\text { Barrameda }\end{array}$ & 05.11 .1540 & $181 \mathrm{r}$ \\
\hline 55 & $\begin{array}{l}\text { Carta a Cristóbal Vaca de } \\
\text { Castro [encargado de proveer } \\
\text { lo conveniente para la quietud } \\
\text { y paz de estos reinos / sobre } \\
\text { la creación de la Audiencia de } \\
\text { Lima] }\end{array}$ & El Rey & $\begin{array}{l}\text { Alcalá de } \\
\text { Henares }\end{array}$ & 01.03 .1543 & $181 \mathrm{r}-182 \mathrm{r}$ \\
\hline 56 & $\begin{array}{l}\text { Carta a Cristóbal Vaca de } \\
\text { Castro [sobre la reformación } \\
\text { y moderación de los } \\
\text { repartimientos de indios] }\end{array}$ & El Rey & Valladolid & 14.05 .1542 & $182 \mathrm{r}-183 \mathrm{r}$ \\
\hline 57 & $\begin{array}{l}\text { Carta a Cristóbal Vaca de Castro } \\
\text { y Francisco Pizarro [sobre la } \\
\text { reformación y moderación de } \\
\text { los repartimientos de indios]. } \\
\text { Va incorporada en la carta } \\
\text { precedente. }\end{array}$ & El Rey & Talavera & 15.04 .1541 & $182 \mathrm{r}-182 \mathrm{v}$ \\
\hline 58 & $\begin{array}{l}\text { Probanzas presentadas por } \\
\text { Cristóbal Vaca de Castro ante } \\
\text { el Consejo de Indias [sobre la } \\
\text { duración de su oficio como } \\
\text { gobernador para evaluar su } \\
\text { salario / sobre la defensa del } \\
\text { virrey Blasco Núnez Vela y lo } \\
\text { que le robó Gonzalo Pizarro] }\end{array}$ & $\begin{array}{l}\text { Testigos: Fray } \\
\text { Pedro de Ulloa, } \\
\text { Alonso Sánchez } \\
\text { de Canales, Fray } \\
\text { Isidro de San } \\
\text { Vicente, Sebastián } \\
\text { de Merlo, Simón } \\
\text { de Cabezuela, } \\
\text { Pedro de Valdés, } \\
\text { Diego de Aguilera, } \\
\text { Juan Velázquez, } \\
\text { Cristóbal de } \\
\text { Barrientos, } \\
\text { Francisco de } \\
\text { Vezerra, García } \\
\text { de Montalvo, } \\
\text { Diego de Aguilera, } \\
\text { Gómez de Rojas, } \\
\text { Juan de Guzmán, } \\
\text { Francisco de las } \\
\text { Valsas, Fray Isidro } \\
\text { de San Vicente, } \\
\text { Diego Mexía, } \\
\text { Pedro de Valdés }\end{array}$ & $\mathrm{s} / 1$ & $\mathrm{~s} / \mathrm{f}$ & $182 \mathrm{v}-186 \mathrm{v}$ \\
\hline 59 & $\begin{array}{l}\text { Publicación de las probanzas. } \\
\text { Traslado a las partes } \\
\end{array}$ & & $\mathrm{s} / \mathrm{l}$ & $\mathrm{s} / \mathrm{f}$ & $186 \mathrm{v}$ \\
\hline 60 & Petición del fiscal Agreda & Lic. Agreda, fiscal & $\mathrm{s} / \mathrm{l}$ & $\mathrm{s} / \mathrm{f}$ & $186 \mathrm{v}$ \\
\hline
\end{tabular}




\begin{tabular}{|c|c|c|c|c|c|}
\hline 61 & \begin{tabular}{|l|} 
Petición en nombre de Cristóbal \\
Vaca de Castro para descargo \\
de los capítulos 2 y 7 [que se \\
incorpore el testimonio de una \\
ejecución de 12000 pesos que le \\
dio doña Francisca Pizarro] \\
\end{tabular} & $\begin{array}{l}\text { Juan de Oribe, } \\
\text { procurador de } \\
\text { Cristóbal Vaca de } \\
\text { Castro }\end{array}$ & Valladolid & 26.06 .1555 & $186 \mathrm{v}-187 \mathrm{r}$ \\
\hline 62 & \begin{tabular}{|l|} 
Testimonio de la ejecución de \\
12000 pesos que doña Francisca \\
Pizarro dio a Cristóbal Vaca \\
de Castro, en Madrid, a 14 de \\
marzo de 1553 \\
\end{tabular} & $\begin{array}{l}\text { Diego de } \\
\text { Hermoza, } \\
\text { escribano de su } \\
\text { Majestad }\end{array}$ & Valladolid & 26.06 .1555 & $187 \mathrm{r}-187 \mathrm{v}$ \\
\hline 63 & $\begin{array}{l}\text { Escritura de obligación sobre } 12 \\
000 \text { pesos que Cristóbal Vaca de } \\
\text { Castro debe a doña Francisca } \\
\text { Pizarro }\end{array}$ & $\begin{array}{l}\text { Cristóbal Vaca de } \\
\text { Castro }\end{array}$ & Los Reyes & 11.10 .1544 & $187 \mathrm{v}-188 \mathrm{v}$ \\
\hline 64 & $\begin{array}{l}\text { Testimonio sobre la } \\
\text { conformidad de la escritura }\end{array}$ & \begin{tabular}{|l} 
Juan Franco, \\
escribano de su \\
Majestad \\
\end{tabular} & $s / 1$ & $\mathrm{~s} / \mathrm{f}$ & $188 \mathrm{v}$ \\
\hline 65 & $\begin{array}{l}\text { Testimonio sobre la entrega de } \\
\text { la dicha escritura a Juan Franco }\end{array}$ & $\begin{array}{l}\text { Diego Gutiérrez, } \\
\text { escribano de su } \\
\text { Majestad } \\
\end{array}$ & Los Reyes & 18.03 .1552 & $189 \mathrm{r}$ \\
\hline 66 & $\begin{array}{l}\text { Relación de la decisión del alcal- } \\
\text { de de dar ejecución a los } 12000 \\
\text { pesos. Pregones. Oposición de } \\
\text { Antonio Vaca en nombre de } \\
\text { Cristóbal Vaca de Castro. }\end{array}$ & & $\mathrm{s} / \mathrm{l}$ & $\mathrm{s} / \mathrm{f}$ & $189 \mathrm{r}-189 \mathrm{v}$ \\
\hline 67 & $\begin{array}{l}\text { Petición de doña Francisca } \\
\text { Pizarro }\end{array}$ & \begin{tabular}{|l|} 
Juan Alonso \\
de Senabria, \\
en nombre de \\
Francisca Pizarro \\
\end{tabular} & $\mathrm{s} / \mathrm{l}$ & $\mathrm{s} / \mathrm{f}$ & $189 \mathrm{v}-191 \mathrm{r}$ \\
\hline 68 & $\begin{array}{l}\text { Relación de probanzas y } \\
\text { escrituras sobre la averiguación } \\
\text { de las partes (Francisca Pizarro, } \\
\text { hija legítima / Antonio y Pedro } \\
\text { de Castro, hijos legítimos) }\end{array}$ & & $\mathrm{s} / \mathrm{l}$ & $\mathrm{s} / \mathrm{f}$ & $191 \mathrm{r}$ \\
\hline 69 & $\begin{array}{l}\text { Testimonio de fe de todo lo } \\
\text { pedido por Cristóbal Vaca de } \\
\text { Castro y el fiscal Agreda }\end{array}$ & \begin{tabular}{|l|} 
Diego de \\
Hermoza, \\
escribano de su \\
Majestad \\
\end{tabular} & $\begin{array}{l}\text { s/l [Valla } \\
\text { dolid] }\end{array}$ & s/f [1556] & $191 \mathrm{r}$ \\
\hline 70 & Sentencia definitiva & $\begin{array}{l}\text { Lic. Tello de } \\
\text { Sandoval, } \\
\text { Lic. Bribiesca, } \\
\text { Lic. Don Juan } \\
\text { Sarmiento, } \\
\text { Dr. Vázquez, } \\
\text { Lic. Villagomez, } \\
\text { del Consejo de } \\
\text { Indias } \\
\end{array}$ & Valladolid & 23.05 .1556 & $191 r-195 r$ \\
\hline 71 & $\begin{array}{l}\text { Suplica en nombre de Cristóbal } \\
\text { Vaca de Castro para que se } \\
\text { mande dar ejecutoria de las } \\
\text { dichas sentencias }\end{array}$ & $\begin{array}{l}\text { Juan de Oribe, } \\
\text { procurador de } \\
\text { Cristóbal Vaca de } \\
\text { Castro }\end{array}$ & Valladolid & 13.02 .1558 & $195 \mathrm{r}-195 \mathrm{v}$ \\
\hline
\end{tabular}


El contenido y la organización de esta documentación permiten despejar incógnitas que las pocas fuentes disponibles sobre el caso del antiguo gobernador habían dejado sin resolver, empezando por el porqué varios cronistas de Indias contrariamente a Garcilaso Inca - lo retratan como un gran defraudador ${ }^{5}$. El pleito entablado por el fiscal Villalobos contiene 21 capítulos, la mayoría de los cuales corresponden a delitos de "soborno". Los demás atañen su responsabilidad como gobernador de Perú y pueden calificarse en dos categorías: la insubordinación, por no cumplir las cédulas y provisiones reales relativas al trato de los indios; la defección, por no presenciar el juicio de residencia conducido por su sucesor o por alejarse del campo de batalla contra Diego de Almagro el Mozo. He aquí los 21 capítulos repartidos según las tres categorías mencionadas:

\begin{tabular}{|c|c|}
\hline \multicolumn{2}{|r|}{ Soborno } \\
\hline Capítulo 2 & $\begin{array}{l}\text { Poner a los indios vacos en cabeza suya y de sus criados debiendo atribuirlos a la } \\
\text { Corona. Los indios que vacaron fueron los de Francisco Pizarro, Diego Méndez, } \\
\text { Pedro Oñate, Juan Vázquez de Osuna, Diego de Almagro, Hernando Pizarro, Juan } \\
\text { de Baldibieso, el Obispo del Cuzco... El beneficio sacado se estima a más de } 100000 \\
\text { castellanos. }\end{array}$ \\
\hline Capítulo 3 & $\begin{array}{l}\text { Estancar en provecho propio la venta de la carne, el maíz y la coca. El beneficio } \\
\text { sacado también se estima a } 100000 \text { castellanos. }\end{array}$ \\
\hline Capítulo 4 & $\begin{array}{l}\text { Apropiarse gran parte de los } 60000 \text { ducados de ropa y de sueldos destinados a las } \\
\text { tropas reales. Poner la ropa en tiendas de Los Reyes y del Cuzco. }\end{array}$ \\
\hline Capítulo 5 & Dar al capitán Peranzures 5000 castellanos de la Hacienda Real. \\
\hline Capítulo 7 & Tomar oro, plata, piedras de valor de 150000 castellanos de la Hacienda Real. \\
\hline Capítulo 8 & $\begin{array}{l}\text { Disimular lo que había sacado de las minas y de los réditos de los indios para no } \\
\text { pagar el Quinto real (estimado a } 50000 \text { castellanos). Usar de manera fraudulenta la } \\
\text { marca del Quinto real. }\end{array}$ \\
\hline Capítulo 9 & $\begin{array}{l}\text { Mandar a España más de } 200000 \text { castellanos escondidamente, registrándolos con } \\
\text { el nombre de sus criados (Diego de Aller, Alonso de Villalobos, Fray Francisco } \\
\text { Martínez, el capitán Peranzures, Francisco Becerra, Juan de Carranza...). }\end{array}$ \\
\hline Capítulo 10 & $\begin{array}{l}\text { Enviar remesas de metales vía Portugal para evitar el control aduanero de la Casa de } \\
\text { Contratación en Sevilla. }\end{array}$ \\
\hline Capítulo 16 & $\begin{array}{l}\text { Dilatar la prisión de Diego de Almagro y Diego Méndez } 5 \text { ó } 6 \text { meses para gozar los } \\
\text { frutos de sus indios. }\end{array}$ \\
\hline Capítulo 17 & $\begin{array}{l}\text { Encomendar indios a sus criados, amigos, parientes y personas de quienes esperaba } \\
\text { favores, intereses y dineros. }\end{array}$ \\
\hline Capítulo 18 & $\begin{array}{l}\text { Recibir por más de } 100000 \text { castellanos de sobornos para dar repartimientos, } \\
\text { gobernaciones, capitanías y otros oficios, para no quitar repartimientos y disimular } \\
\text { culpados. Percibir en lugar de la Hacienda real más de } 150000 \text { castellanos. }\end{array}$ \\
\hline Capítulo 20 & $\begin{array}{l}\text { Enviar dádivas de oro y otras cosas a los miembros del Consejo de Indias y sus } \\
\text { mujeres para anular sus culpas en las tomas de la Hacienda real y de particulares. }\end{array}$ \\
\hline Capítulo 21 & $\begin{array}{l}\text { Detener mucho tiempo los navíos en los puertos para aprovecharse más de la } \\
\text { Hacienda real y de los repartimientos de indios. }\end{array}$ \\
\hline \multicolumn{2}{|r|}{ Insubordinación } \\
\hline Capítulo 1 & $\begin{array}{l}\text { Obligar a los indios a transportar cargas excesivas con sus ropas, haciendas y las de } \\
\text { sus criados. }\end{array}$ \\
\hline Capítulo 6 & $\begin{array}{l}\text { Echar a los indios a las minas, sin pagarles sus jornales. El beneficio sacado se } \\
\text { estima a } 100000 \text { castellanos. }\end{array}$ \\
\hline
\end{tabular}




\begin{tabular}{|l|l|}
\hline Capítulo 12 & $\begin{array}{l}\text { Incumplir las cédulas sobre el buen trato de los indios cargándolos, echándolos a las } \\
\text { minas y llevándoles los tributos. }\end{array}$ \\
\hline Capítulo 13 & Descuidar la Hacienda real. \\
\hline Capítulo 14 & $\begin{array}{l}\text { Desatender su función para ocuparse en cosas suyas particulares (granjear minas, } \\
\text { cobrar para sí tributos que pertenecían a la Corona, rescatar indios, vender ropas } \\
\text { y mantenimientos para su cuenta, cobrar para sí los bienes de los culpados en la } \\
\text { muerte de Francisco Pizarro). }\end{array}$ \\
\hline Capítulo 19 & $\begin{array}{l}\text { Levantar a los pueblos del Perú contra el virrey Blasco Núñez Vela y los oidores } \\
\text { de la Audiencia de Lima que llevaban ordenanzas reales para promulgar las Leyes } \\
\text { Nuevas. }\end{array}$ \\
\hline \multicolumn{2}{|c|}{ Defección } \\
\hline Capítulo 11 & $\begin{array}{l}\text { Huir de Perú sin hacer la residencia. Esconderse y desviar su camino hacia las } \\
\text { Azores. }\end{array}$ \\
\hline Capítulo 13 & No volver a España ni enviar persona con poder para hacer la residencia. \\
\hline Capítulo 15 & $\begin{array}{l}\text { Apartarse con 40 soldados a caballos en guarda de su persona durante la guerra } \\
\text { contra Diego de Almagro. }\end{array}$ \\
\hline Capítulo 21 & $\begin{array}{l}\text { Detener mucho tiempo los navíos en los puertos para que los miembros del Consejo } \\
\text { no fuesen avisados de sus culpas. }\end{array}$ \\
\hline
\end{tabular}

Los cargos imputados a Cristóbal Vaca de Castro apuntan su total incompetencia para la función de gobernador. Como el uso lo requería, fue su sucesor en el cargo, el virrey Blasco Núñez Vela, quien llevó a cabo el juicio de residencia mencionado en los capítulos 11 y 13 de la acusación. Las pesquisas preliminares desde la Audiencia de Panamá condujeron al virrey a llamar la atención del rey en una carta del 15 de febrero de 1544, donde señala «la cantidad de gente del Perú» que habla mal de Vaca de Castro y como tiene averiguado que «ha enviado a España gran cantidad de oro y ninguno en su nombre», recomendando que se «cata[se] su casa secretamente» (Colección Muñoz A110, t. 65, f. 246). El juicio de residencia se realizó en mayo de 1544, es decir un año antes del pleito conducido por el fiscal del Consejo de Indias, y concluyó con 27 cargos $^{7}$. En ambas acciones de justicia las acusaciones coinciden y parecen constituir la cara de una misma moneda.

Miremos, por ejemplo, cómo en diversos capítulos - 2, 17, 18 y 19 - del pleito, Vaca de Castro fue acusado de quebrantar el artículo de las Leyes Nuevas que prohibía los nuevos repartimientos de indios, cuando en el juicio de residencia Núñez Vela apuntó graves deficiencias en su aplicación durante el gobierno de su predecesor: no sólo reformó a los indios de los primeros conquistadores para remunerar a sus amigos (cargos 7 y 20), sino que «retubo en su cabeça los indios que fueron del dicho Diego de Almagro e Diego Mendez e Oñate e algunos de los yndios que fueron del marqués Pizarro fasta que bino en estos reynos el visorrey e audiençia» (cargos 15, 17) y "escri[bió] a los cabildos que diesen y enbiasen poder para suplicar de las ordenanças nuevas de su magestad» (cargo 22). Asimismo, tanto el fiscal Villalobos como el virrey Núñez Vela apuntaron el mal trato que recibieron los indios al echarlos Vaca de Castro en las minas en condiciones infrahumanas (capítulos 6 y 12 en el pleito, cargos 18 y 19 en el juicio de residencia). Estas coincidencias no son las únicas. También en ambas 
documentaciones se evocan: los sobornos que recibió el gobernador del Perú para dar repartimientos, gobernaciones, capitanías y otros oficios, para no quitar repartimientos y disimular culpados (capítulo 18 del pleito, cargos 1, 2, 4, 6, 8 del juicio de residencia); el estancar en provecho propio la venta de la carne, el maíz y la coca (capítulo 3 del pleito, cargo 5 del juicio de residencia). Las pesquisas de Núñez Vela permitieron identificar a los «criados» de Vaca de Castro, cuyos nombres se vuelven a mencionar en el pleito: el capitán Peranzures, Diego de Aller, fray Francisco Martínez, Francisco Becerra, Juan de Carranza, Gaspar Gil... La originalidad del juicio de residencia, por haberse realizado las pesquisas en Perú, estriba en los relatos a veces muy detallados de testigos locales que ofrecen un retrato vivo de la sociedad limeña y cuzqueña de aquella época ${ }^{8}$. En resumidas cuentas, debido a las coincidencias referidas, creemos que el fiscal Villalobos se inspiró en el juicio de residencia - incluso podemos preguntarnos si tuvo a la mano una copia del documento. En este caso, cabría la posibilidad de que la residencia encargada al virrey Núñez Vela en 1544 constituyese una etapa preliminar y un pedido extraoficial del Consejo de Indias, o directamente del Rey, con vistas al pleito contra el antiguo gobernador. Nótese que el fiscal entabló el pleito entre junio y julio de 1545, cuando el protector de Vaca de Castro en el Consejo de Indias, el cardenal García de Loaysa, a quien debía su nombramiento, se encontraba debilitado $\mathrm{y}$ a pocos meses de fallecer.

Cierta firmeza prevaleció en el tratamiento del caso del antiguo gobernador, como lo prueba el lapso que separan las primeras acusaciones depositadas el 29 de junio y el 20 de julio de 1545 con la primera revisión el 19 de abril de 1554; fueron casi nueve años, durante los cuales Vaca de Castro permaneció encarcelado. De hecho, Carlos V resistió varios años para concederle la reposición. Así lo menciona el biógrafo Antonio de Herrera a Pedro de Castro: «No quiero callar que he hallado que el Consejo consultó varias veces al Emperador la inocencia del señor Vaca de Castro y que al cabo de ocho años le envió a Flandes una muy apretada consulta, y su Majestad Cesárea la tuvo cinco o seis años en un escritorio hasta que la resolvió; tan porfiado estuvo a creer las siniestras relaciones de la imprudencia de Blasco Núñez Vela» (Pérez de Tudela XXXIII).

A pesar de las consultas para que se revisara la sentencia, de las distintas probanzas que presentó, así como de dos peticiones de reconvención contra el fiscal Villalobos, Vaca de Castro hubo que esperar 11 años para que se pronunciaran su absolución y su liberación, después de la segunda revisión del caso el 23 de mayo de 1556. ¿Cómo explicar la dilación del Rey y su firmeza en la resolución de este caso? Pensamos que la toma de posición de Vaca de Castro en contra de la aplicación de las Leyes Nuevas, fervorosamente defendidas por Bartolomé de Las Casas y sus partidarios en la corte, tuvo un impacto importante. En Perú, el asunto era espinoso, debido a las protestas de los encomenderos que encontraron respaldo en las filas de Gonzalo Pizarro (1544-1548) y Francisco Hernández Girón (1553). Ahora bien, Vaca de Castro contribuyó a la emergencia de esta situación, con su gestión poco 
pacificadora de las disputas entre pizarristas y almagristas y la cruel represión que aplicó a estos últimos ${ }^{9}$. El gobierno de quien se esperaba que hiciera justicia entre ambos bandos rivales y «apaciguase» el Perú defraudó sobremanera; después de la muerte, el exilio o el encarcelamiento de los líderes de la conquista de Perú y sus principales capitanes, Vaca de Castro procedió a un nuevo reparto de las encomiendas, cediendo las más codiciadas a sus allegados o personas influentes a cambio de favores y dinero, cuando no se las reservaba para sí mismo. De modo que una fila de beneméritos resentidos, los que se quedaron sin nada, dirigieron sus quejas a la Corona pidiendo el reemplazo de Vaca de Castro. El portavoz de estos resentidos era sin lugar a dudas el contador Juan de Cáceres, a quien Vaca de Castro había negado las encomiendas del obispo del Cuzco; se trasladó a la Audiencia de Panamá desde principios de 1543 para hacer más efectivas las quejas del cabildo de Lima y organizar la oposición contra el Gobernador:

«[...] es necesario proveer para el remedio de la más rica y abundante tierra de oro y plata que hay en el mundo, la cual agora está la más perdida que hay en él, é si con brevedad no se envía persona celosa del servicio de Dios é de Vuestra Majestad, é que no tenga codicia, como la tiene el que de presente la gobierna, se acabará de perder é destruir. Él ha hecho un gran tesoro, porque todos los indios questán vacos, que son en gran cantidad, les tiene puestos en su cabeza [...] los que tienen calidades é merecimientos en la tierra, mueren de hambre; todos viven descontentos» (Medina 1895, tomo VI: 262) ${ }^{10}$.

«Tiene en sí todo lo habido en los rebeldes [almagristas], de que pudiera haber aplicado a vuestro fisco más de 200000 castellanos; todos sus repartimientos dellos tiene en su cabeza y de sus criados; algunos repartimientos vende públicamente. El se trata como Rey, y no se acordó de las necesidades de V. M. de manera que dando de sí la tierra tanto, no habrá en todo este año para acabar de pagar los gastos de la guerra pasada. El cabildo de la ciudad y los oficiales de Los Reyes viendo esto y que lo de V. $M$. se repartía entre vocingleros y compañeros, y que estaban sin libertad, acordaron viniese yo a informar a esta Audiencia y pasar si fuere necesario a la corte» (Colección Muñoz, A110, tomo 65: fol. 101v-102v] $)^{11}$.

Finalmente, el anuncio de la llegada del virrey Núñez Vela con las ordenanzas de aplicación de las Leyes Nuevas vino a contrariar no sólo las ambiciones frustradas de los que pedían su parte sino también la buena marcha de esta corrupción bien engrasada implementada por Vaca de Castro. La supresión de todo nuevo repartimiento significaba el colapso de este sistema de cohecho y explica por qué Vaca de Castro encontró el favor de los encomenderos alterados, poniéndose un momento en el lugar que ocuparía luego Gonzalo Pizarro.

Con todo, es probable que la resistencia del Rey para conceder la reposición a Vaca de Castro tenga otro motivo. Eran bien conocidos y documentados sus delitos de malversación. En una carta que escribió a su esposa doña María de Quiñones, el 28 de noviembre de 1542, el entonces gobernador del Perú dejó constancia de sus 
actos delincuentes. No sólo confirmaba haber concedido repartimientos a personas de quienes esperaba favores (capítulo 17 del pleito), sino que también sugería a su esposa sobornar a personas de influencia, como los consejeros de Indias o sus mujeres (capítulo 20), guardar «secreto» sobre lo que ella recibía, así como fingir necesidad para que el Rey y sus privados le hiciesen más mercedes:

«Sy a vuestra merçed paresçiere que conviene tomar trabajo de hablar sobre ello [mis méritos] al comendador mayor [Francisco de los Cobos] y secretario Sámano, y cardenal [García de Loaysa] y conde de Osorno y los del Consejo de Indias, hacerlo heys, porque hará provecho; y para lo uno y lo otro ayudaros heys del presidente del Consejo Real, que pues yo he dado acá a su hermano un repartimiento de indios muy buenos, y con una myna de plata muy rica, hallándole a puerro [sic] en aquella mala tierra de Cali, obligaçion tiene de hazer bien lo que me tocare. $Y$ también os ayudad de la señora doña María de Mendoça, mujer del señor comendador mayor; que pues yo tengo cuidado de servir a todos, razón es que en esto me lo agradezcan y paguen; y pues yo, señora, lo he trabajado y lo merezco, bien es que allá se trabaje por aver algún provecho y se porfie que lo hagan, porque destos servicios tales que hazen caballeros, se suelen començar las casas y mayorazgos» (Cartas de Indias 1877: 496; énfasis mío).

«Y quando vuestra merçed oviere de yr a casa de alguno de los que he dicho, yd honradamente en vuestra mula [...]. Una cosa que aveys de tener en gran cuidado y poner muy gran diligencia en ello, y es que todo lo que allá oviere ydo y agora llegare, lo recibays muy secreto, y aun los de la casa no lo sepan, y lo tengays secreto fuera de casa en algún depósito de monasterio [... y aveys de fingir neçesydad y que yo no he ynbiado nada, sino çiertos dineros para pagar a Hernando Romano y Juan Navarro quatro myll castellanos que tomé allá prestados para my viaje; y con esto, se disimulará todo lo otro. [...] y esto todo conviene, porque, aunque todo es poco, mientras menos viere el Rey y sus privados, más mercedes me harán» (Cartas de Indias 1877: 496, 499; énfasis mío).

De la lectura de la misma misiva, se colige que Vaca de Castro mandaba regularmente dinero a su esposa, de manera encubierta, registrándolo en nombre de Diego de Aller, Alonso de Villalobos o fray Francisco Martínez (capítulo 9). Por fin, se colige que sacó beneficio de la venta de ropa en Perú (capítulo 4). Esta carta la interceptó en Panamá Juan de Cáceres, quien la remitió a Carlos V junto con informes y pruebas en que se extendía sobre la conducta del gobernador del Perú12. Sabemos que el Rey tuvo conocimiento de dicha carta por la firma, las rúbricas, las acotaciones y la manecilla que puso en las márgenes y al pie el secretario real en el Consejo de Indias, Juan de Sámano (Cartas de Indias 1877: 663, 854-856). Viendo su nombre aparecer entre los funcionarios a corromper, Juan de Sámano, se escandalizó y llamó la atención del monarca sobre este asunto. A partir de entonces la correspondencia de Vaca de Castro con su esposa recibió especial atención por parte del Rey, quien en mayo de 1550 mandó al corregidor de Arévalo donde estaba preso Vaca de Castro que tomase juramento de calumnia y recibiese la declaración del reo "por virtud de ciertas censuras en que viene inserta una carta que Doña María de 
Quiñones, mujer del Lycenciado Vaca de Castro, de nuestro Consexo, escribió al dicho su marido por donde dize manifestarse much a cantidad de oro e plata, e xoyas e otras cosas que el dicho Lycenciado Vaca de Castro abia enbiado encubiertamente» (Torres de Mendoza 1884: 457-458). Las revelaciones de Juan de Sámano eran tan estratégicas como necesarias para un personaje de su rango ya que había tratado con Vaca de Castro para que cobrara en su nombre las ganancias de las minas que le pertenecían en Perú y de la escribanía que había recibido de la gobernación de Nueva Toledo ${ }^{13}$ (Archivo General de Indias, Sevilla [AGI], Justicia, 467, No 1, f. 121v.). De hecho, en 1547, Sámano disputó en corte a Vaca de Castro varias sumas de dinero que le debía del tiempo en que le dio poder para que dispusiese en su nombre de la dicha escribanía ${ }^{14}$ (AGI, Justicia, 1175, Nº; AGI, Justicia, 1053, №3).

En los mismos años, el Rey y sus consejeros recibieron más pruebas del comportamiento fraudulento de Vaca de Castro: el celoso fiscal Villalobos diligenció una encuesta desde agosto de 1545, o sea pocos días después del depósito de las acusaciones el 29 de junio y el 20 de julio, con el fin de comprobar si Vaca de Castro y su sobrino Alonso de Montalvan gestionaron la venta de metales preciosos y esmeraldas en Lisboa sin registrarlos en la Casa de Contratación de Sevilla ${ }^{15}$ (AGI, Justicia, 1174, No2, R.3). Los autos pronunciados por el Príncipe el 18 y el 21 de agosto de 1545 indican que la Corona miraba con atención el caso de Vaca de Castro y que los interrogatorios de los marineros, plateros y comerciantes de la ciudad portuguesa confirmaron las sospechas de Villalobos ${ }^{16}$. En fin, el fraude se juzgaba tan excesivo (sobre todo porque en muchos casos redundaba en perjuicio del fisco) y las peticiones para que Vaca de Castro dejase el cargo de gobernador ${ }^{17}$ eran tan numerosas ${ }^{13}$ que el Rey lo apartó durante mucho tiempo de la vida política y manifestó cierta intransigencia cuando, varios años más tarde, en 1552, el Consejo de Indias examinaba las peticiones de revisión que recibía por parte de la defensa:

"Cuanto al negocio del licenciado Vaca de Castro habemos visto lo que nos consultáteis, y pues teneis acordado lo que con él debe hacerse, será bien que pronunciéis la sentencia conforme a lo que consultais excepto en dos artículos: el uno, de la suspensión de la plaza del Consejo por seis años, en lo cual nos ha parecido que se debe poner privación de la dicha plaza; lo otro es en lo de su carcelería, la cual no se debe alzar, si no consintiese la sentencia y se cumpliese y ejecutase; y así lo debeis pronunciar y declarar, pues no se la ha de alzar la carcelería sino en caso de que haya consentido la privación. No habrá para que avisar a los del Consejo de que no le admitan suplicación de la sentencia» (Cartas de Indias 1877: 855).

El reinado de Carlos I concluyéndose, terminadas las guerras civiles de los españoles en Perú, Vaca de Castro obtuvo finalmente la revisión de su proceso en 1554 y 1556. Con la absolución, recuperó las investiduras prometidas cuando se marchó a Perú - el hábito de Santiago y una magistratura en el Consejo de Indias gracias a una estrategia de defensa ofensiva. La ejecutoria muestra cómo todas sus decisiones materiales, políticas y guerreras se justificaron como la respuesta legíti- 
ma e ineluctable del «buen gobernador» a la amenaza tajante que constituía Diego de Almagro el Mozo. La rebeldía de éste se aprecia de distintas maneras en la documentación - colusión con el enemigo extranjero, crimen de lesa majestad, anarquía, secta - pero siempre como un peligro inminente para la monarquía. De modo que la victoria de Vaca de Castro en Chupas se presenta como un acto heroico que aureola su gobierno en Perú. La presencia en el archivo de una copia del proceso criminal que mandó llevar contra Diego de Almagro el Mozo y sus secuaces en el mismo campo de batalla (Archivo de la Abadía del Sacromonte, Granada [AAS], volumen 7 del fondo «Vaca de Castro» $)^{18}$ sugiere con fuerza toda la importancia que revistó este argumento en la defensa de Vaca de Castro. El alegato debió de convencer al Consejo de Indias ya que desde la revisión de 1554, el nuevo fiscal, el licenciado Agreda, fue obligado a abandonar las penas criminales y conformarse con pedir penas pecuniarias, centrándose en los delitos relativos a la gestión lucrativa de los repartimientos de indios (AAS, Ejecutoria, f. 179v-180r).

Esta presentación general de la ejecutoria permite hacerse una idea más precisa de la génesis del pleito entablado por el Consejo de Indias contra Vaca de Castro, el detalle de los cargos, los fundamentos de la defensa, las grandes etapas del procedimiento y su desenlace. Nos conduce a contemplar al gobernador del Perú como un hombre ambicioso y avisado, dotado de cierto maquiavelismo en el sentido propio del siglo XVI, es decir de una marcada inclinación por el arte de la política, y detrás de quien se destaca otra figura relevante, la de su hijo, don Pedro de Castro y Quiñones. Ambos defendieron con tenacidad y habilidad la imagen de su linaje manchada por las sospechas y condenas relativas a una insaciable - aunque bastante común durante la colonización de las Indias - voracidad económica. Esta documentación también revela una faceta menos conocida de Vaca de Castro como a un personaje fragilizado, controvertido por sus contemporáneos y aislado un buen tiempo de la vida política metropolitana. Grandeza y decadencia resumen la vida de este hombre un tanto olvidado por la historia actual y que rescatamos como una prueba viva de la potestad implacable que la Corona y su brazo procesal en el Consejo de Indias impusieron ya no sólo a los primeros conquistadores - bastante conocidas son las querellas contra los Colón, Pizarro y Cortés - sino a sus propios oficiales.

\section{Notas}

1 Quedó inédita hasta 1804, cuando se publicó un compendio de textos del cronista (Zamácola). Hubo que esperar el siglo XX para que se publicara una edición completa (Herrera y Tordesillas).

2 Estos seis cuadros, casi desconocidos, están conservados en la galería de la abadía del Sacromonte frente al archivo actual; fueron reproducidos por Paniagua Pérez y Viforcos Marinas (1991). Según la Dra. María Luisa García Valverde, la serie inicial se componía de cuatro cuadros sobre el buen gobierno de Vaca de Castro: 1) su intervención decisiva en la batalla de Chupas; 2) la condena de Diego de Almagro el Mozo por traición y las negociaciones de paz con él; 3) su ejecución; 4) la llegada del Virrey Blasco Núñez Vela y la rebelión de Gonzalo Pizarro. Se añadieron luego dos 
cuadros más, situados cronológicamente al principio y al final de los demás cuatro, tratándose de representar la llegada de Vaca de Castro a Perú y su huída del mismo lugar. Encargados a un autor anónimo por Pedro de Castro, se realizaron en Granada entre 1614 y 1615.

3 Archivo General de Indias, Sevilla [AGI], Justicia, 1174, N.2, R.3: Información y probanza hecha por el licenciado Juan de Villalobos, fiscal del Consejo, para el pleito que trata con el licenciado Cristóbal Vaca de Castro, sobre cierta cantidad de oro, plata y esmeraldas que trajo desde Indias a Portugal sin registrar. La fecha es la del traslado. 26.03.1546. AGI, Indiferente general, 738, N.188: ubicado en las consultas del Consejo de Indias, el documento citado ratifica la absolución de Cristóbal Vaca de Castro por el Consejo de Indias y recuerda los cargos por los que había sido condenado diez años atrás. Archivo General de Simancas, Valladolid [AGS], Estado, 64, f. 50 y 501, f. 63v-64r y 70v: esta correspondencia entre Carlos V y el príncipe Felipe pone en evidencia las vacilaciones del rey sobre las condiciones de detención del antiguo gobernador del Perú. Finalmente, será trasladado de su residencia en Valladolid a la cárcel de Arévalo.

4 A cargo de Álvaro M. de la Borda Espinoza y Deysi A. Zambrano Flores (bajo la dirección de Mariusz Ziółkowski).

5 Cieza de León (1994: 305-306) subraya la codicia desaforada de Vaca de Castro: «no entendía en más que en buscar dineros para henchir la gran codiçia que tenía. Caso harto feo, pues enviándolo Su Majestad a que toviese el reyno en justicia e le gobernase con retitud, procurava de allegar tesoros por vías no lícitas, pues afirman que tenía grandes yntelijençias para lo poder hacer». Gonzalo Fernández de Oviedo (1959: 243, 247) evoca por su parte la «insaciable cobdicia» del licenciado Cristóbal Vaca de Castro.

6 No confundir con Juan de Villalobos, el fiscal que dirigió el proceso contra Vaca de Castro.

7 Archivo General de Indias, Sevilla [AGI], Justicia, 467, $\mathrm{N}^{\circ} 1$.

8 A este respecto son dignos de interés los relatos sobre los matrimonios arreglados por Vaca de Castro entre sus «criados» y viudas dotadas de buenos repartimientos (f. 158v), las esmeraldas que adquirió por intercesión de Sebastián Sánchez Merlo (f. 112v-116v), los tributos de indios que percibió (f. 116v-121r, 157r-158r), los intercambios con Paullu Inca por el intermedio del lengua Martín (f. 110r-111r).

$9 \quad$ AGI, Justicia, 467, f. 109r, 159r. En el juicio de residencia (cargo 12), el virrey Blasco Núñez Vela denuncia la crueldad de Vaca de Castro con los almagristas, a quienes mandó cuartear someramente, después de la batalla de Chupas. Los descuartizamientos ordenados por Vaca de Castro también fueron mencionados por Juan de Cáceres (Medina 1895, tomo VI: 261), así como Cieza de León (1994: 292-295), López de Gómara (1999: 217). La sentencia que pronunció Vaca de Castro contra Diego de Almagro y sus secuaces en Chupas el 16 de septiembre de 1542 alude expresamente a ese tipo de castigo. Archivo de la Abadía del Sacromonte, Granada [AAS], Ejecutoria, f. 139r: «que sean hechos quartos e puestos los dichos quartos en palos por los caminos públicos».

10 Carta de Juan de Cáceres al Rey, 11 de marzo de 1543.

11 Carta de Juan de Cáceres al Rey, 18 de agosto de 1543. Véase también la carta del Alcalde, Regidores y Oficiales Reales de Lima del 6 de marzo de 1543 (Colección Muñoz A102, tomo 57: fol. 57r). En Cuzco, las quejas contra Vaca de Castro emanaron del regidor de la ciudad, Francisco Maldonado, en una carta del 9 de marzo de 1543: «V. M. hará muy señaladas merçedes à todos los vasallos que acá estamos de V. M., de nos proveer de remedio y con toda brevedad, porque asi lo hemos menester, y que V. M. nos envie su Real Audiençia y visorrey que nos tenga en justicia, à quien todos los de acá deseamos [...] a más de siete meses que toda la tierra y gran suma de repartimientos que están vacos, se la tiene en sí, y no los a proveido à nadie de los servidores que V. M. acá tiene» (Cartas de Indias 1877: 523).

12 Carta de Juan de Cáceres al Rey, 18 de agosto de 1543 (Colección Muñoz, A110, tomo 65: f. 101v-102r): "Yo pedi que un oidor fuese a tomar $v$ [isit] a a Vaca, y tener la tierra en justicia hasta la venida de Núñez Vela. Mandaronme dar fianzas de mil castellanos para la pena si no probaba. Los deposité y di información bastante que embio a V. M. Aqui todos están espantados como fue provisto en tal cargo un tal mal hombre, mentiroso, vanaglorioso [...] todos están a la mira a ver el castigo ejemplar que V. M. manda hacer por sus atroces delitos. [...] Se han tomado los despachos, las cartas e instrucciones que [Vaca de Castro] envía para sus criados y su mujer. Van para V. M. Los mande abrir. Por ellos se verificaron sus liviandades y el mucho oro y plata y joyas y esmeraldas que ha 
enviado y envía y le queda». Véase también la carta de la Audiencia de Panamá al Rey, 3 de agosto de 1543 (Colección Muñoz, A110, tomo 65: f. 101v).

13 AGI, Justicia, $467, \mathrm{~N}^{\circ} 1$, f. $121 \mathrm{v}$.

14 AGI, Justicia 1175, Nº . AGI, Justicia, 1053, Nº3.

15 AGI, Justicia, 1174, N², R.3.

16 AGI, Justicia, $1159, \mathrm{~N}^{\circ} 12$.

17 Además de las denuncias del virrey Núñez Vela (nota 7), del regidor de Cuzco Francisco Maldonado y del contador Juan de Cáceres (notas 10, 11 y 12), véase la relación del licenciado Martel de Santoyo al Rey (Lisson Chávez 1943: 99) y la sentencia del Consejo de Indias (Levillier, tomo II: 301-315).

18 El Proceso hecho ante Vaca de Castro en los Reynos del Perú, contra Don Diego de Almagro y sus secuaces lleva la fecha del 16 de agosto de 1542. Fue publicado integralmente en 2010 (Ziółkowski y Espinoza de la Borda).

\section{Referencias citadas}

\section{Calero Palacios, María del Carmen}

1999 La Abadía del Sacromonte de Granada. Catálogo de manuscritos. Editorial de la Universidad de Granada, Granada.

Cárdenas Bunsen, José

2014 Correspondencia privada e historia pública: las relaciones intelectuales de Pedro de Castro, Antonio de Herrera y el Inca Garcilaso. Colonial Latin American Review 23 (3): 413-438.

\section{Cartas de Indias}

1877 Cartas de Indias. Ministerio de Fomento, Madrid. Versión digitalizada: openlibrary.org.

Cieza de León, Pedro

1994 Crónica del Perú. Cuarta Parte. Vol. II Guerra de Chupas. Pontifica Universidad Católica del Perú/Academia Nacional de Historia, Lima.

Colección de don Juan Bautista Muñoz

2010 Colección de don Juan Bautista Muñoz. Real Academia de la Historia, Madrid. Versión digitalizada en DVD-Rom.

Fernández de Oviedo, Gonzalo

1959 Historia general y natural de las Indias. Biblioteca de Autores Españoles CXXI. Atlas, Madrid.

Guzmán Palomino, Luis

2009 Corrupción, separatismo y comuna en la guerra de Vaca de Castro contra Diego de Almagro el Mestizo. Cantuta 17. Documento electrónico: http://fr.calameo.com/read/ 000116093509f4370f82f].

Herrera y Tordesillas, Antonio de

1918 Elogio de Vaca de Castro. (edición de Juan Francisco V. Silva). Madrid.

Levillier, Roberto

1921-1926 Gobernantes del Perú, cartas y papeles, siglo XVI: documentos del Archivo de Indias. Sucesores de Rivadeneyra, Madrid. 
Lisson Chávez, Emilio

1943 La Iglesia de España en el Perú. Colección de documentos para la historia de la Iglesia en el Perú, que se encuentran en el Archivo General de Indias. Vol. I, núm. 3. Sevilla.

López de Gómara, Francisco

1999 Historia General de las Indias. (prólogo y cronología de Jorge Gurria Lacroix). Edición digital basada en la edición de Caracas, Biblioteca Ayacucho, 1978. Biblioteca virtual Miguel de Cervantes, Alicante. Documento electrónico: http://www.cervantesvirtual.com/nd/ark: /59851/bmcz8963.

Medina, José Toribio

1895 Colección de documentos inéditos para la historia de Chile. Tomos VI y VII. Santiago de Chile.

Padre García, Casiano (O.S.A.)

1957 Vida de don Cristóbal Vaca de Castro. Presidente y Gobernador del Perú. Ediciones Religión y Cultura, Madrid.

Paniagua Pérez, Jesús y María Isabel Viforcos Marinas

1991 El leonés Don Cristóbal Vaca de Castro, gobernador y organizador del Perú. S. A. Hullera vasco-leonesa, S.L.

Torres de Mendoza, Luis (director)

$1884 \quad$ Colección de documentos inéditos relativos al descubrimiento, conquista y organización de las posesiones españolas en América y Oceanía, sacados, en su mayor parte, del Real Archivo de Indias. Tomo 42. Imprenta de Manuel G. Hernández, Madrid. Versión digitalizada: Aecid http:// bibliotecadigital. Documento electrónico: aecid.es/bibliodig/es/consulta/registro.cmd?id=1118.

Vargas Ugarte, Rubén

1959 Dos cartas inéditas de don Francisco Pizarro y fray Vicente Valverde. Revista de Historia de América 47: 152-162.

Zamácola, Juan Antonio de

1804 Discursos morales, políticos e históricos de don Antonio de Herrera, cronista del rey don Felipe II, autor de las Décadas de Indias y otras muchas obras. Tomo I. Imprenta de Ruiz, Madrid.

Ziółkowski, Mariusz y Álvaro Espinoza de la Borda

2010 Cristóbal Vaca de Castro contra Diego de Almagro «El Mozo»: Nuevos documentos sobre la «Guerra de Chupas» en el Archivo de la Abadía del Sacromonte de Granada (España). Estudios Latinoamericanos 30: 215-346.

Ziółkowski, Mariusz y Ximena Fernández Fontenoy

2011 El obispo fray Vicente de Valverde y el proceso sobre los «rescates ilícitos»: nuevo documento del Archivo de la Abadía del Sacromonte de Granada (España). Estudios Latinoamericanos 31: 145-176. 
